\title{
The Consumer Behavior of Children Toward Digital Audiovisual Advertising
}

\author{
Arius Krypton ${ }^{1}$ \\ ${ }^{1}$ Communication lecturer, Vocational Education Program, Universitas Indonesia \\ *Email: arie_krypton08@yahoo.com
}

\begin{abstract}
This study examined the consumer behavior displayed by children toward digital advertising. Children's marketing is a very competitive domain. In the current era of digitalization, sometimes digital audiovisual advertising is the only medium through which marketers can communicate with children. Hence, the study of this area of marketing is critical. This study observed children's exposure to digital audiovisual advertising through YouTube and assessed its communication outcome. It was found that children's consumer behavior can be predicted from their awareness of digital audiovisual advertising and their ability to influence their parent's purchasing decisions. Children's preferences for the products that are advertised, the themes of the advertisements, and the types of YouTube advertising were also identified in this research project.
\end{abstract}

Keywords: children, consumer, behavior, digital, advertising, YouTube

\section{Introduction}

McNeal (1992) stated that youngsters aged between four and twelve amassed an aggregate of US $\$ 31.3$ billion in the form of remittances, occupations, and endowments, and that they spent around $92 \%$ of this amount. The control of children over their cash exerts sweeping impact as verified by Ty Consolidated: the company sold Beanie Children for about $\$ 6$ each, which is the precise sum of the average weekly allowance given to youngsters in the United States by their parents (Kotler, 2000). The children's section is a vital potential market that is currently targeted by numerous businesses that observe their purchasing choices and market influence. Nowadays, children are believed to have certain necessities and are thought to own the spending power to fulfill those needs.

The "influence factor" of children on their parents has been studied for its effects on the buying of products ranging from new cars to frozen pizzas. McNeal (1987) mentioned that around 17 billion dollars' worth of new vehicles are sold as a result of children's preferences of the brand and type they want their parents to purchase. For instance, the minivan was designed for children who requested more space.

In Indonesia, numerous advertising organizations target youngsters through their choices of characters, colors, and music. Such examples of advertising meant for children may be seen in children-focused products. Goods such as toys and foods are marketed to the child rather than to the parent. Examples of such products include cereal (Koko Krunch), candies (Jagoan Neon), milk (Nestle and Ultra Jaya), and family restaurants (McDonald and KFC). Advertisements for general items that target children may also be found, for example, in sectors such as broadcast communications (Telkomsel) and even real estate (Meikarta). These illustrations demonstrate that in the current market, communication agencies have realized the significance of youngsters as a target audience and have noted the potential impact of children on the adult market.

McNeal (1992) referred to reasons why advertisers focus on youngsters as a consumer segment:

1. Children hold three markets at once:

a. The essential market. They have their own cash, their own needs, and the capacity and eagerness to spend on items that fulfill their needs.

b. The impact showcase. They can impact others such as their family members or guardians both directly and indirectly with regard to purchase decisions.

c. The future market. Retailers plan to gain brand loyalty as the youngsters grow up by "catching them young."

2. They have their funds to spend for future products and services.

3. The young population has the opportunity to spend on anything it desires: both food and non-food items, electronic products, hobby-related products or services, and entertainment. 
4. They might be engaged in the buying decisions of other shoppers by framing assessments, recognitions, and inclinations pertaining to outlets such as mass merchandizers, markets, and restaurants.

These imperative attributes persuade advertisers to target children and to attempt to establish a relationship that is demonstrated as critical to sales numbers. McNeal (1992) remarked that while the US\$6 billion a year spent by youngsters is not an enormous amount for advertisers, the conceivable lifetime effect on spending is much more impressive. Consequently, a great extent of showcasing exercises are focused on children, and YouTube is one of the main media channels used to promote and publicize products to millennials.

Scientists have investigated the impact of digital audiovisual advertising on the young population since the early 1990s (Sherry et al., 1999). Alluring promotions can apply a huge and quick impact on the consumer behavior of children, especially their procurement conduct and demands. Youngsters are easily influenced by publicity and tend to buy and demand the items they regularly see promoted. On the other hand, when they are not swayed by marketing strategies, they are less awed and would not attempt to purchase the items being promoted.

The present examination centers around two phenomena:

1. Determining the impact of the attitudes of children toward audiovisual digital advertising on their familiarity with the promotions, their buying conduct, their effect on parents, and their buying choices of the publicized items.

According to Churchill (1991), the mindfulness of young people alludes to their perspective or understanding of the actualities with regard to specific articles or wonders. How much a child influences the buying decisions of parents suggests how much information the young population collects toward big and small family buys (Sherry et al., 1999). The buying conduct of children indicates their intent to follow up on the promotion of an item (Solomon, 1994). Throughout the course of this investigation, these factors mentioned above (familiarity with promotions, buying conduct, effect on parents, and buying choices of publicized items) mirrored the reactions of children toward the promotions and will thus elucidate the extent of the comprehension of the young people with regard to promotions.

2. Identifying the inclinations of children for items, themes, and types of audiovisual digital advertisements through YouTube.

Rossiter (1977) has established the standard estimation of the conduct of children toward discrete media publicity. Rossiter's investigation included pre-tried disposition proclamations that reflected a scope of subjective and emotional responses toward varying media plugs.

\section{Method}

\section{Inspecting Strategy}

This study conducted surveys for students at Indonesian elementary schools in SDN Cirimekar in the Cibinong area of West Java. A total of 252 Indonesian youngsters between the ages of 7-12 years were randomly selected for participation in the study. The arbitrary example strategy was used for the overview. The poll was translated into Bahasa to inspire better comprehension from the children. The response rate received from the surveys was $100 \%$, and every participant who took an interest in the research was rewarded with a snack.

A pilot test was conducted before examining the results of the survey. The primary reason for this test was to measure the affectability of the inquiries in the survey to verify the absence of ambiguities. A few adjustments were made, including in the scale design. All responses were estimated on a 6-point scale for the pilot test (emphatically settle on a truce unequivocally), which evinced unsatisfactory and wavering quality levels, a = 0.28. Thus, answers were estimated on a 4-point scale (firmly settle on a truce unequivocally) for the actual survey.

\section{The Reactions of Youngsters to Advertisements}

Ten items were utilized to quantify the children's reactions to digital audiovisual advertising. The greater portion of the inquiries were framed and were adjusted from previous research (McNeal, 1992; Gunter \& McAleer, 1997; Gunter \& Furnham, 1998). A 4-point scale (firmly settle on a truce unequivocally) was used, and the factors were broken down to decide on the applicable measurements. Weak items were discarded before the actual investigation.

Three measurements pertaining to children's reactions to advertising were apprehended: their consciousness of YouTube promotions, their effect on their guardians' shopping choices, and their buying conduct. Despite the 
reactions initially comprising ten items, two were eliminated in light of irrelevant stacking. The steadiness of the quality evaluation with regard to the three measurements resulted in two being chosen: children's mindfulness with $\alpha=0.62$ and children's impact with $\alpha=0.66$. The measurement of the buying conduct of young people was discarded because of its low alpha estimation of $\alpha=0.16$. This finding upheld the elucidation offered by Gunter and Furnham (1998) that noteworthy issues will be confronted while inspecting the connection between television advertising and the qualities, conduct, and buyer related discernments of children. According to Gunter and Furnham (1998), advertising is altogether different from other types of promotions. Regardless of whether the advertising produces a positive attitude toward goods, the attitude does not translate naturally into buying conduct for children. The connections between states-of-mind and behavior are perplexing and are unreliable. Consequently, it is difficult to propose any conclusive actual impact of commercials on the buying behavior of young people.

Numerous past investigations have attempted to tender an adequate answer to questions regarding the impact of TV promotions on the buying conduct of young boys and girls. However, the research strategy utilized is instrumental to the discovery of appropriate responses. For instance, exploratory investigations have largely bolstered the opinion that advertising exerts substantial impact on children but other studies have recorded that this influence is low. Without a doubt, the most examinations that fall into this latter classification underscore that television commercials form just one of numerous means of promotions that attempt to influence the buying conduct of children. Guardians, companions, and social circumstances also exert an impact (Gunter \& Furnham, 1998).

\section{Estimating the States-of-Mind of Youngsters}

Rossiter's examination estimated the attitudes of children toward television promotions on a 7-point scale. The chosen measure centered on the intellectual and emotional responses of youngsters toward television advertising in relation to factors such as apparent honesty, potentially irritating characteristics, objectivity in depicting items, general affection, level of persuasion, authenticity of characters, and dependability (Pereira, 1996).

\begin{tabular}{cc}
\hline & Table 1 Seven Material Measurements \\
\hline Honesty & YouTube Commercials tell the truth \\
Disturbing & YouTube Commercials are annoying \\
Too Good & YouTube Commercials tell only the good side of the product not the bad \\
Like & I like many YouTube Ads \\
Persuade & YouTube Ads try to encourage viewers to buy products that they don't need \\
Believe & You can always trust what people say or do in YouTube Ads \\
Best & Products with many ads on YouTube are the best product to purchase \\
\hline
\end{tabular}

\section{Polling Plan}

An image scale was utilized as a part of this overview. Figure 1 describes the scale, where smiling and sad faces were used as markers of the reactions of the participating children. As indicated by Malhotra (1993), the metaphorical scale demonstrates extremely value when the respondents are young. The investigation was completely self-administered and the only help provided was to answer a few inquiries.

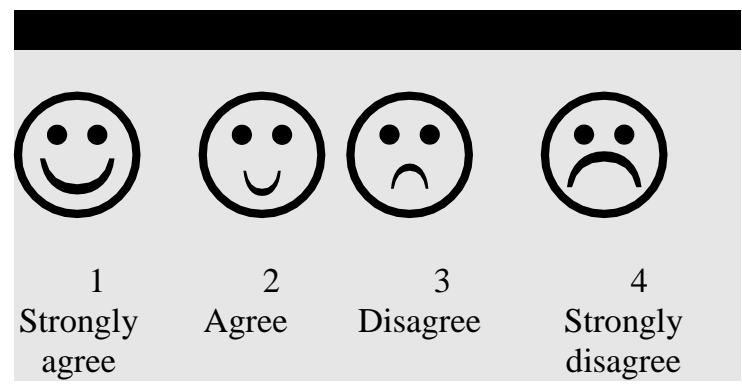

Figure 1. The figurative scale 


\section{Limitations of the Investigation}

The constraints of this study can be condensed into three points. The first pertains to the cost associated with the undertaking of the examination and the restriction of time. The survey was implemented only on grade school students in SDN Cirimekar situated in Cibinong, West Java, Indonesia. Consequently, the research speaks to only a small part of the Indonesian populace. Second, despite the application of a basic and arbitrary testing strategy, the manner in which the researcher was permitted to include just a couple of classes from each school made it difficult to generalize the discoveries. Third, the investigation assumes that the participants watched YouTube commercials, and that they comprehended the ads that they watched.

\begin{tabular}{ccc}
\hline \multicolumn{3}{c}{ Table 2. Information Characterization $(\mathbf{N}=252)$} \\
\hline Age (Years) & Frequency & $\%$ \\
$\mathbf{7}$ & 40 & 15.8 \\
$\mathbf{8}$ & 41 & 16.2 \\
$\mathbf{9}$ & 45 & 17.8 \\
$\mathbf{1 0}$ & 41 & 16.2 \\
$\mathbf{1 1}$ & 44 & 17.4 \\
$\mathbf{1 2}$ & 41 & 16.2 \\
& Sex & \\
\hline Male & 128 & 54 \\
\hline Female & 124 & 46 \\
\hline & & \\
\hline
\end{tabular}

The sample attributes of the 252 respondents are outlined in Table 2. As apparent from the table, the youngsters in each age group are more or less equivalently distributed. A slight difference may be observed in the sex ratio as more young men were incorporated into the study than young women. This sample can certainly be said to reflect the profile of the Indonesian populace. As is illustrated in Table 3, the examination similarly delivered an overview of the inclinations of Indonesian youngsters concerning the narratives, subjects, and items that are promoted.

\begin{tabular}{llll}
\hline \multicolumn{4}{c}{ Table 3 Children's advertising preferences (N=252) } \\
\hline Advertising type & Frequency & Ranking & $\%$ \\
\hline Story advertising & 223 & 1 & 92.5 \\
\hline Food-related Advertising & 207 & 2 & 82.2 \\
\hline Non-food advertising & 63 & 3 & 25.0 \\
\hline $\begin{array}{l}\text { Advertising Theme } \\
\text { Humorous Advertising }\end{array}$ & Frequency & $\%$ \\
\hline Musical Advertising & 191 & 75.8 \\
\hline Colorful Advertising & 185 & 73.4 \\
\hline Advice Characteristics & 98 & 38.9 \\
\hline Advertising for all ages & 80 & 31.7 \\
\hline $\begin{array}{l}\text { Based on the type } \\
\text { Food-related Advertising }\end{array}$ & 67 & 26.6 \\
\hline $\begin{array}{l}\text { Fruits/ Real or Beverages } \\
\text { Mineral water in packaging }\end{array}$ & & \\
Vegetables & & \\
\hline Non-food Advertising & 213 & 84.5 \\
\hline $\begin{array}{l}\text { Attire advertising } \\
\text { Publication/ book }\end{array}$ & 140 & 55.6 \\
\hline
\end{tabular}




\begin{tabular}{lllllll}
\hline \multicolumn{7}{c}{ Table 4 Children's behavior inter-item correlation } \\
\hline Item & Disturbing* & Too Good* & Like & Persuade* & Honesty & Best \\
Honesty & 0.22 & 0.10 & 0.24 & 0.16 & 0.17 & 0.15 \\
Disturbing * & & 0.16 & 0.31 & 0.33 & 0.22 & 0.21 \\
Too Good* & & 0.8 & 0.10 & 0.05 & 0.14 \\
Like & & & 0.25 & 0.14 & 0.19 \\
Persuade* & & & & 0.24 & 0.19 \\
Best & & & & 0.25 \\
\hline \multicolumn{7}{c}{ *Reverse score }
\end{tabular}

The inner consistency dependability of Rossiter's scales, with a $=0.69$ was additionally tried with item explanations as appeared in Table 2.

Among the variables recorded in Table 1, "disturbing," "too good," and "persuade" were reverse coded as proposed by Rossiter (1997). The discoveries abridged in Table 4 show that all but two of the variables were found to be positively significant, and were within the range of 0.10 to 0.60 . As per the Guilford-Fruchter rules for an all-around built test, the correlation between connections ought to be in the vicinity of 0.10 and 0.60 (Pereira, 1996). The present finding implies that Rossiter's (1977) scale can be used in the study of an Indonesian sample to ascertain mentalities relating to digital audiovisual commercials.

A second examination was performed on the data to comprehend the relative commitment of autonomous factors to the children's states-of-mind toward digital audiovisual commercials. In light of the investigation, the biggest indicator of children's states-of-mind was their familiarity with YouTube advertisements $b=0.20, p=0.03$, as opposed to their effect on what their parents buy with $b=0.11, p=0.09$. The regression model proved to be important at $\mathrm{R}=0.25, \mathrm{p}=0.00$

\section{Results and Discussion}

As indicated by the aforementioned tables, the Indonesian youngsters' first inclination was to notice advertisements that appealed through humor. Next, in line were promotions that involved music, songs, or voiceovers. The most popularly reported were those that were identified with the children's most loved pastimes (e.g., cartoons, and rivalry promotions), followed by sustenance and non-nourishment ads. As indicated by the review, Indonesian youngsters prefer purchasing organic products (in packaging or fresh), drinking water, vegetables, clothes, and books. It was also noted during the study that children were enthusiastic about a wide range of items. Their consistent requirement for an assortment of products explains why the young population needs an array of items and further, how it communicates its requirement for new encounters, sensations, and rewards (McNeal, 1992).

It is vital for advertisers to study the phenomena that interest children so that they can discover the products that would most appeal to them. For instance, do they, for the most part, consider purchasing snacks and desserts with which youngsters are characteristically related? The outcomes demonstrate that the food-related interests of Indonesian youngsters include more natural products (84.5\%), drinking water (55.6\%), and vegetables (46.4\%). Apart from edibles, the children looked for opportunities to purchase attire/fashion (67.9\%), followed by books $(63.5 \%)$.

Reliability tests on the youth's perception of YouTube promoting find considerable support for Rossiter's scale and in this way increase trust in its appropriateness. The results evince that Rossiter's (1977) scale can be helpfully associated to Indonesian youngsters to determine their attitudes to YouTube advertising despite the fact that the review covered merely a small part of West Java.

The sample reactions of youngsters to YouTube promotions are fascinating. The mindfulness of Indonesian children and their effect on parental buys are indicators of the Indonesian youngsters' attitudes toward digital audiovisual advertising. The children's mindfulness is the principle indicator as opposed to their impact on parental buys. The more positive their reaction, the more positive their mentalities toward the promotions. According to Sherry et al. (1998), the relapse models have similarly neglected to represent critical measures of fluctuation despite the utilization of instruments from past research, presumably because respondents accomplished the survey on their own. In past research, their family members have commonly been requested to help with their responses. 


\section{Conclusion}

The present study demonstrates that Indonesian youngsters are conscious of YouTube promotions and that they influence the buying decisions made by their guardians. These two factors are critical indicators of the conduct of children with regard to television commercials. Despite the impact of YouTube promotion not being the primary influence on the purchase decisions made by youngsters, the channel does impinge upon their consumer conduct and practices, whether in the form of the child's own purchase or a purchase made as a result of prodding parents to buy an item. It has likewise been demonstrated that the younger the children, and the lower their socio-economic background, the more vulnerable they are to the impact of audiovisual advertising (Gunter \& Furnham, 1998).

The second objective of this review was satisfied by the discoveries of the participants' inclinations concerning the items, the promotional narratives, and the themes of the advertising. The outcomes mirrored the youngsters' socialization as buyers. Thus, the inclinations of Indonesian youngsters with regard to promotion attributes should not be overlooked by sponsors. Generally speaking, the findings of the investigation are helpful for most advertisers in deciding their techniques of targeting young Indonesian shoppers. However, marketers should practice caution since they could be scrutinized for invigorating interest in an audience that is unable expend too much money.

As a future research project, this study proposes that researchers should conduct the same examination in other populations by using the Rossiter scale to determine whether similar outcomes may apply to various youth audiences. The results of such geographically and culturally varied studies would be valuable to business leaders, economic analysts, open strategy specialists, and sociologists. Future research should delve into different factors, for example, extraordinary nationalities. The study would be even more interesting if it could scrutinize contrasts among children spanning across discrete states, societies, and cultures.

\section{Acknowledgment}

The authors wish to recognize and thank Universitas Indonesia, especially the vocational education program of the communication department for its help in numerous aspects.

\section{References}

Bearden, W. O., Teel, J. E., \& Wright, R. R. (1979). Family income effects on measurement of children's attitudes toward television commercials. Journal of Consumer Research, 6(3), 308-311.

Bergler, R. (1999). The effects of commercial advertising on children. International Journal of Advertising, 18(4), 411-425. Churchill, G. A. (1991). Marketing research: Methodological foundations. Orlando: Dryden Press.

Confos, N., \& Davis, T. (2016). Young consumer-brand relationship building potential using digital marketing. European Journal of Marketing, 50(11), 1993-2017.

Edmond, S. (2006). Advertising to children: A changing media landscape. Young Consumers, 7(4), 8-12.

Eshghi, A., Sarkar, J. G., \& Sarkar, A. (2017). Impact of online advertising on adolescent's brand attitudes. Marketing Intelligence and Planning, 35(6), 706-723.

Evra, V. J. (1990). Television and child development, children youth and Family Consortium. Electric clearinghouse.

Gunter, B., \& Furnham, A. (1998). Children as consumers: A psychological analysis of the young People's market. Great Britain, UK: Routledge.

Gunter, B., \& McAleer, J. (1997). Children and television. Great Britain, UK: Redwood Books.

Khandeparkar, K. (2016). Influence of media context on humorous advertising effectiveness. Journal of Research in Interactive Marketing, 9(4) 299-312.

Kotler, P. (2000). Marketing management: The millennium edition. Englewood Cliffs, NJ: Prentice Hall.

Kujur, F., \& Singh, S. (2018). Emotions as predictor for consumer engagement in YouTube advertisement. Journal of Advances in Management Research, 15(2), 184-197.

Kurp Maher, J., Lord, J. B., Shaw Hughner, R., \& Childs, N. M. (2006). Food advertising on children's television. Young Consumers, 7(4), 41-52.

Lascu, D.-N., Manrai, A. K., Manrai, L. A., \& Brookman Amissah, F. (2013). Online marketing of food products to children: The effects of national consumer policies in high-income countries. Young Consumers, 14(1), 19-40.

Lindquist, J. D., \& Belonax, J. J. (1979). A reliability evaluation of a short test designed to measure children's attitudes toward advertising in audio-visual and print media. Advances in Consumer Research, 7, 676-679.

Malhotra, N. K. (1993). Marketing research: An applied orientation. Englewood Cliffs, NJ: Prentice Hall. 
Martin, M. C. (1997). Children's understanding of the intent of advertising: A meta-analysis. Journal of Public Policy and Marketing, 16(2), 205-216.

McNeal, J. U. (1987). Children as consumers. United States of America: D.C Heath and Company.

McNeal, J. U. (1992). Kids as consumers: A handbook of marketing to children. NY: Macmillan, Inc. McNeal, J. U., \& Ji, M. F. (1999). Chinese children as consumers: An analysis of their new product information sources. Journal of Consumer Marketing, 16(4), 345-365.

Pereira, A. (1996). Measuring children's attitudes towards television commercials: Assessing the internal consistency of scale in Latvia. Journal of Euro-Marketing, 5, 7-15.

Peter, J. P., \& Olson, J. C. (1994). Understanding consumer behaviour. United States of America: Irwin, Inc.

Riecken, G., \& Samli, A. C. (1981). Measuring children's attitudes toward television commercials: Extension and replication. Journal of Consumer Research, 8(1), 57-61.

Rose, G. M., Bush, V. D., \& Kahle, L. (1998) The Influence of Family Communication Patterns on Parental Reactions toward Advertising: A Cross-National Examination. Journal of Advertising, 27(4), 71-85.

Rossiter, J. R. (1977). Reliability of a short test measuring children's attitudes toward TV commercials. Journal of Consumer Research, 3(4), 179-184.

Sherry, J., Greenberg, B., \& Tokinoya, H. (1999). Orientations to TV advertising among adolescents and children in the US and Japan. International Journal of Advertising, 18(2), 233-250.

Solomon, M. R. (1994). Consumer behavior. Massachusetts: Allyn and Bacon.

Unnikrishnan, N., \& Bajpai, S. (1996). The impact of television advertising on children. New Delhi: SAGE Publications India, Pvt, Ltd.

Yang, K.-C., Huang, C.-H., Yang, C., \& Yang, S. Y. (2017). Consumer attitudes toward online video advertisement: YouTube as a platform. Kybernetes, 46(5), 840-853. 